“A Three-Level dc-dc Converter for Bipolar dc Power Grids: Analysis and Experimental Validation," IEEE IECON Industrial Electronics Conference, Singapore (virtual conference), Oct. 2020.

This material is posted here with permission of the IEEE. Such permission of the IEEE does not in any way imply IEEE endorsement of any of Group of Energy and Power Electronics, University of Minho, products or services. Internal or personal use of this material is permitted. However, permission to reprint/republish this material for advertising or promotional purposes or for creating new collective works for resale or redistribution must be obtained from the IEEE by writing to pubs-permissions@ieee.org. By choosing to view this document, you agree to all provisions of the copyright laws protecting it. 


\section{A Three-Level dc-dc Converter for Bipolar dc Power Grids: Analysis and Experimental Validation}

\author{
Vitor Monteiro \\ Centro ALGORITMI \\ University of Minho \\ Guimaraes, Portugal \\ vmonteiro@dei.uminho.pt
}

\author{
Tiago J. C. Sousa \\ Centro ALGORITMI \\ University of Minho \\ Guimaraes, Portugal \\ tsousa@dei.uminho.pt
}

\author{
Delfim Pedrosa \\ Centro ALGORITMI \\ University of Minho \\ Guimaraes, Portugal \\ dpedrosa@dei.uminho.pt
}

\author{
Sergio Coelho \\ Centro ALGORITMI \\ University of Minho \\ Guimaraes, Portugal \\ sergio.coelho@algoritmi.uminho.pt
}

\author{
Joao L. Afonso \\ Centro ALGORITMI \\ University of Minho \\ Guimaraes, Portugal \\ jla@dei.uminho.pt
}

\begin{abstract}
The concept of bipolar dc power grids has emerged, mainly due to the improvements in efficiency and offered flexibility when compared with unipolar architectures. Though, concerns of asymmetrical loads affecting voltage unbalances is the key challenge to overcome. In this context, power electronics play an important influence since the features of the topology contribute to define the quality of the bipolar de power grids. This paper presents the application of a bipolar bidirectional three-level (BB3L) dc-dc converter as a contribution to mitigate the aforementioned concern of bipolar dc power grids. The proposed BB3L dc-dc converter is introduced, and an insightful description of its principle of operation is presented throughout the paper. Since the BB3L dc-dc converter operates with three voltage levels, it is possible to diminish the blocking voltage of the switching devices, representing an important feature of such topology. Additionally, it can operate with the voltage and current variables controlled with the double of the switching frequency, also representing an added value of such topology. The distinct possibilities of operation are presented, both in buck-mode and boost-mode, and an experimental validation is presented to validate the main features of the BB3L dc-dc converter for bipolar de power grids.
\end{abstract}

Keywords-Bipolar dc Power Grids, Three-Level Converter, dc-dc Converter, Bidirectional Converter.

\section{INTRODUCTION}

As extensively announced and discussed, the subject of sustainable electrical energy is suitable for forthcoming generations, where the smart grids emerge as an enrichment to support this topic [1-6]. In this context, and also taking into account the nature of some technologies that are coupled to the power grid, the battle of ac power grids vs. dc power grids has been reactivated [7][8]. Specifically, the introduction of renewables (e.g., photovoltaic panels), the supporting systems of energy storage (e.g., batteries), and the electric mobility paradigm (e.g., hybrid and electric vehicles) have contributed decisively to the possibility of shifting ac power grids to dc power grids. In fact, the power grids of nowadays are fronting a deeply transformation toward dc grids, mainly due to the new technologies that are being endorsed. Detailed reviews regarding dc power grids in terms of applications, power controllability, stabilization procedures, and standardization are presented in [9] and [10]. As a contribution to introduce more and more dc grids, the selection of voltage levels based on a compromise among compatibility, protection, and efficiency is introduced in [11]. A distribution system based on a dc power grid contemplating the introduction of sensitive electrical appliances is proposed in [12]. A hierarchical control of dc power grids with a high penetration of renewables is proposed in [13]. The operation modes for urban dc power grids are proposed in [14]. A flexible control regarding power flow in dc power grids is proposed in [15]. The perspective and analysis of dc substations for dc power grids, regarding the distinct arrangements and control plans, are investigated in [16] and [17]. Innovative architectures of dc power grids, as a new generation of power distribution grids, are investigated in [18]. The power flow regulation among distinct $\mathrm{dc}$ power grids is presented in [19]. An analysis regarding a future power electronics power grid is explored in [20]. General reviews of dc-dc topologies of power converters for dedicated dc power grids are presented in [21] and [22]. Globally, as leading advantages of dc power grids, it can be highlighted: (i) Reduced number of power conversion stages (mostly, a single power stage is used); (ii) Issues of reactive power, harmonic pollution, and voltage/current unbalances are nonexistent; (iii) Improved efficiency, since the voltage drops in the lines are reduced; (iv) Robustness, flexibility and reliability. Despite the aforementioned advantages, the proliferation of dc power grids is facing two important challenges: the standards and the protections, including short circuit faults and grounding [10][23]. As a contribution to this field, it can be highlighted the documentation introduced by the European Union (defining the voltage limits between $75 \mathrm{~V}$ and $1500 \mathrm{~V}$ ) [24]. Nowadays, two main architectures are identified for dc power grids, namely the unipolar and the bipolar [10]. The unipolar architecture is categorized by establishing a single dc voltage level using a two-wire configuration. On the other hand, the bipolar architecture is categorized by establishing two dc voltage levels using a three-wire configuration [25][26]. By comparing both 
architectures, it is possible to recognize that the unipolar is inherently less complex, both in terms of power structure and control. However, the bipolar architecture offers more flexibility to accommodate dc technologies with different voltage levels, allowing more efficient power stages, and offers a neutral conductor, permitting to explore situations of a line fault. An ample review of emerging technologies for bipolar dc power grids is presented in [27]. Despite the advantages, bipolar dc power grids can have problems of unbalances, depending on the linked technologies and the operation (i.e., consuming or injecting power). Therefore, it is convenient the utilization of dedicated power converters for balancing currents in dc power grids, contributing to improve the stability, as proposed in [28].

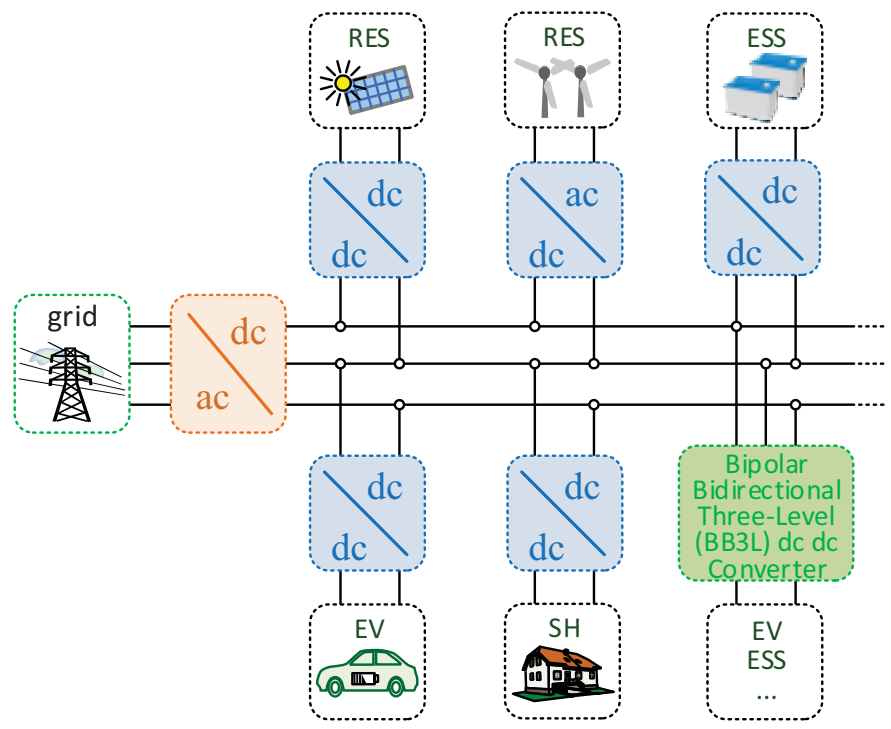

Fig. 1. Common configuration of a bipolar de power grid, highlighting the proposed bipolar bidirectional three-level (BB3L) dc-dc converter.

Fig. 1 shows a common configuration of a bipolar de power grid, where it is possible to identify the dc interface of renewable energy sources (RES), based on photovoltaic panels and micro wind turbines, the interface of energy storage systems (ESS), the interface of dc smart homes $(\mathrm{SH})$, and the interface of electric vehicles (EV) [29][30][31][32]. Traditionally, these technologies are linked to the bipolar dc power grid with a two-wire dc-dc power converter, contributing to accentuate the unbalances. As a support to mitigate this critical aspect, this paper focuses on the application of the bipolar bidirectional three-level (BB3L) dc-dc converter to interface some of the aforementioned applications, e.g., since it is bidirectional it is ideal to interface ESS or EV. The topology of the BB3L dc-dc converter is presented in Fig. 2, where it is verified that it is based on a split dc-link on the dc side $d c \# 1$ to interface the bipolar dc grid. Additionally, four power switches $\left(s_{1}, s_{2}, s_{3}, s_{4}\right)$ are necessary for obtaining a bidirectional and a three-level voltage operation $\left(v_{B B 3 L}\right)$. The power switches are controlled in pairs: during the buck-mode are controlled the power switches $s_{1}$ and $s_{4}$, while during boost-mode are controlled the power switches $s_{2}$ and $s_{3}$. The voltage assumed by the BB3L dc-dc converter $\left(v_{B B 3 L}\right)$ is dependent of the voltage level on both dc side interfaces. As main contributions of this paper, it can be highlighted: (i) Analysis and application of the BB3L dc-dc converter and its operation framed with bipolar dc power grids; (ii) A dc-dc converter capable of diminishing the voltage stress of each switching device (half of the voltage of the dc side $d c \# 1$ ), when compared with the traditional solutions, representing an interesting possibility to bipolar dc power grids; (iii) BB3L dc-dc converter capable of operating similarly to an interleaved mode, diminishing the requirements of passive filters, representing an interesting possibility for bipolar dc power grids; (iv) Experimental validation of the BB3L dc-dc converter in the context of bipolar dc power grids.

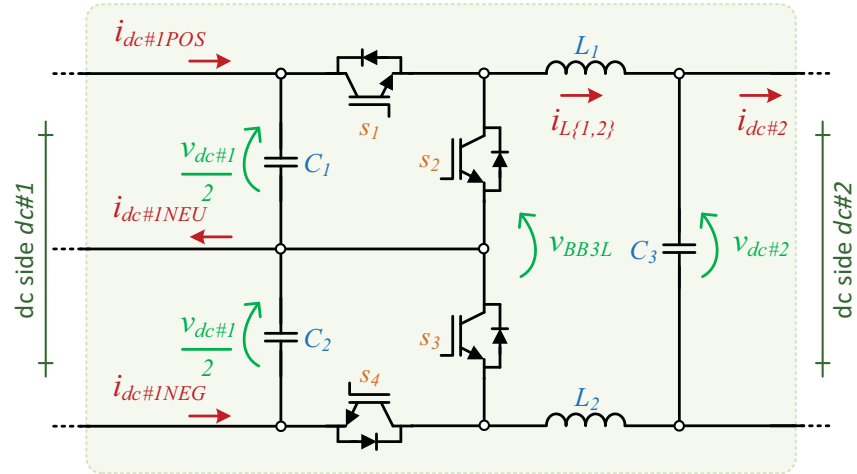

Fig. 2. Topology of the bipolar bidirectional three-level (BB3L) dc-dc converter.

\section{BiPOLAR BIDIRECTIONAL THREE-LEVEL DC-DC CONVERTER: CONTROL STRATEGY}

Examining Fig. 2 on the dc side $d c \# 2$ in terms of voltages during the buck-mode, it can be described:

$$
-v_{L 1}(t)-v_{L 2}(t)-v_{d c \# 2}(t)+v_{B B 3 L}(t)=0,
$$

where $v_{B B 3 L}$ is the voltage assumed by the converter, $v_{L 1}$ and $v_{L 2}$ correspond to the instantaneous voltages in the inductors $L_{l}$ and $L_{2}$ and $v_{d c \# 2}$ is the voltage in the dc side $d c \# 2$. Considering that the current in the inductor $L_{1}$ is equal to the current in the inductor $L_{2}$, equation (1) can be simplified, yielding:

$$
-\frac{d i_{L\{1,2\}}(t)}{d t}\left(L_{1}+L_{2}\right)-v_{d c \# 2}(t)+v_{B B 3 L}(t)=0 .
$$

The voltage $v_{B B 3 L}$ is controlled according to the duty-cycle and the voltage on the dc side $d c \# 1$, i.e., a reference $v_{B B 3 L}$ is compared with the pulse-width modulation (PWM) carriers to obtain the state of each power switch, defining the voltage $v_{B B 3 L}$. This variable is directly dependent of the current, which is the variable that must be controlled. In other words, the current is controlled according to its reference, resulting in a reference voltage $v_{B B 3 L}$ during each sampling period $[k, k+1]$. By applying the forward Euler method, the digital implementation of (2) yields:

$$
\begin{gathered}
\frac{\left(i_{L\{1,2\}}[k+1]-i_{L\{1,2\}}[k]\right)}{T_{S}-v_{B B 3 L}[k]=0 .}\left(L_{1}+L_{2}\right)+v_{d c \# 2}[k]- \\
-1 .
\end{gathered}
$$

Analyzing this digital implementation, the current $i_{L_{\{}\{, 2\}}[k+1]$ is the current of the BB3L dc-dc converter $\left(i_{L_{\{1}\{, 2\}}\right)$ at the end of the sampling period $[k, k+1]$. Therefore, instead of $i_{L\{1,2\}}[k+1]$, it is considered the respective reference current. It is important to note that the reference current can be established by applying different methods according to the application, e.g., for electric mobility applications it can be established by the battery 
management system and for ESSs it can be established by the power management of the smart grid (e.g., balancing the power production and consumption). Taking into account the objective of controlling the current in the inductors $L_{\{1,2\}}$ with the double of the switching frequency (permitting to reduce the value of the passive filters when compared with the traditional dc-dc half-bridge converter), two carriers are used in the PWM. During the buck-mode, the reference voltage $v_{B B 3 L}$ is compared with a carrier $C_{l}$ to obtain the PWM for the power switch $s_{1}$ and compared with the carrier $C_{2}$ to obtain the PWM for the power switch $s_{4}$. By examining Fig. 2 on the de side $d c \# 2$ in terms of voltages during the boost-mode, it can be described:

$$
-v_{L 1}(t)-v_{L 2}(t)+v_{d c \# 2}(t)+v_{B B 3 L}(t)=0,
$$

where $v_{B B 3 L}$ is the voltage assumed by the converter. As the current in the inductors $L_{1}$ and $L_{2}$ is equal, equation (4) can be simplified as:

$$
-\frac{d i_{L\{1,2\}}(t)}{d t}\left(L_{1}+L_{2}\right)+v_{d c \# 2}(t)+v_{B B 3 L}(t)=0 .
$$

As implemented to the operation in buck-mode, the digital implementation of (5) is described by:

$$
\begin{gathered}
\frac{\left(i_{L\{1,2\}}[k+1]-i_{L\{1,2\}}[k]\right)}{T_{S} \quad}\left(L_{1}+L_{2}\right)-v_{d c \# 2}[k]+ \\
+v_{B B 3 L}[k]=0 .
\end{gathered}
$$

Also, in the boost-mode, two carriers are used in the PWM. The reference voltage $v^{*}{ }_{B B 3 L}$ is compared with a carrier $C_{I}$ to obtain the PWM for the power switch $s_{2}$ and compared with the carrier $C_{2}$ to obtain the PWM for the power switch $s_{3}$.

\section{BIPOLAR BIDIRECTIONAL THREE-LEVEL DC-DC CONVERTER: COMPUTATIONAL VALIDATION}

\section{A. Operation in Buck-Mode}

Fig. 3 shows the results obtained during the operation of the BB3L dc-dc converter in buck-mode, taking into account that the voltage on the dc side $d c \# 2$ is lower than half of the voltage on the dc side $d c \# 1$. In this case, a voltage of $400 \mathrm{~V}$ on the dc side $d c \# 1$ and a voltage of $150 \mathrm{~V}$ on the dc side $d c \# 2$ were considered. Fig. 3(a) shows the current on the dc side $d c \# 2\left(i_{L\{1,2\}}\right)$ properly controlled according to a reference of $10 \mathrm{~A}\left(i^{*}{ }^{\{}\{1,2\}\right)$. In Fig. 3(b), Fig. 3(c), Fig. 3(d) are shown the currents on the dc side $d c \# 1$, respectively, the currents $i_{d c \# I P O S}, i_{d c \# I N E U}$, and $i_{d c \# I N E G}$. As it can be seen, the currents $i_{d c \# I P O S}$ and $i_{d c \# I N E G}$ present the same waveform, but with a phase shift of 180 degrees between them. The current $i_{d c \# I N E U}$ results from the sum of the $i_{d c \# I P O S}$ and

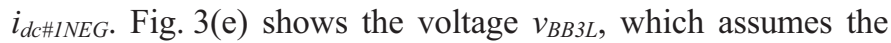
values of $0 \mathrm{~V}$ or $200 \mathrm{~V}$, corresponding to half of the voltage $v d c \# 1$, i.e., it assumes only two values. This situation occurs because the voltage $v d c \# 2$ is lower than half of the voltage $v d c \# 1$. Fig. 3(f) shows the instantaneous powers on the dc side $d c \# 1$, where both are found to have the same waveform, but have a 180 degree phase shift between them. Finally, in Fig. 3(g) are shown the carriers $C_{I}$ and $C_{2}$ (with a phase shift of 180 degrees between them) and the reference $v_{B B 3 L}^{*}$. Analyzing Fig. 3 as a whole, there are five well-defined moments for each switching period. In the case (i), when the variable $v_{B B 3 L}$ is lower than the carrier $C_{l}$ and higher than the carrier $C_{2}$, the BB3L dc-dc converter assumes the voltage value $v_{d c \# I} / 2$, the current on the $\mathrm{dc}$ side $d c \# 1$ increases, the current $i_{d c \# I P O S}$ increases and the current $i_{d c \# I N E G}$ increases. In this way, the instantaneous power $p_{d c \# I P O S}$ increases and the instantaneous power $p_{d c \# I N E G}$ decreases.

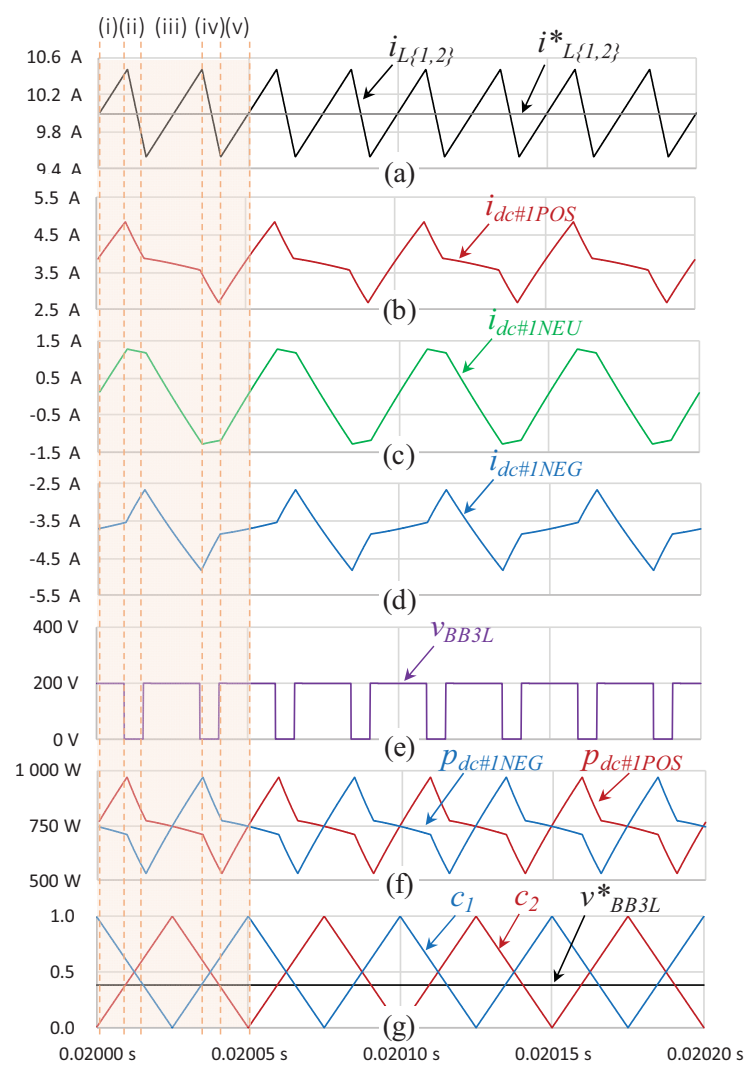

Fig. 3. BB3L dc-dc converter during the operation in buck-mode with the voltage on the dc-side $d c \# 2$ lower than half of the voltage on the dc-side $d c \# 1$ : (a) Current on the dc-side $d c \# 2\left(i_{L\{1,2\}}\right) ;(\mathrm{b})(\mathrm{c})(\mathrm{d})$ Currents on the dc-side $d c \# 1$ ( $i_{d c \# I P O S}$, $\left.i_{d c \# I N E U}, i_{d c \# I N E G}\right)$; (e) Voltage assumed by the converter $\left(v_{B B 3 L}\right)$; (f) Instantaneous powers on the dc-side $d c \# 1 ;(\mathrm{g})$ PWM carriers $\left(c_{\{1,2\}}\right)$ and reference voltage of the converter $\left(v^{*}{ }_{B B 3 L}\right)$.

In the case (ii), when the variable $v^{*}{ }_{B B 3 L}$ is lower than the carrier $C_{1}$ and lower than the carrier $C_{2}$, the converter assumes the voltage value 0 , the current on the dc side $d c \# 1$ decreases, the current $i_{d c \# I P O S}$ decreases and the current $i_{d c \# I N E G}$ increases. In this way, the instantaneous powers $p_{d c \# I P O S}$ and $p_{d c \# I N E G}$ decrease. In the case (iii), when the variable $v^{*}{ }_{B B 3 L}$ is higher than the carrier $C_{1}$ and lower than the carrier $C_{2}$, the converter assumes the voltage value $v_{d c \# 1} / 2$, the current on the dc side $d c \# 1$ increases, the current $i_{d c \# I P O S}$ decreases and the current $i_{d c \# I N E G}$ decreases. In this way, the instantaneous power $p_{d c \# I P O S}$ decreases and the instantaneous power $p_{d c \# I N E G}$ increases. In the case (iv), when the variable $v_{B B 3 L}^{*}$ is again lower than the carrier $C_{l}$ and lower than the carrier $C_{2}$, the converter assumes the voltage value 0 , the current on the dc side $d c \# 1$ decreases, the current $i_{d c \# I P O S}$ decreases and the current $i_{d c \# I N E G}$ increases. In this way, the instantaneous powers $p_{d c \# I P O S}$ and $p_{d c \# I N E G}$ decrease. In the case (v), when the variable $v_{B B 3 L}^{*}$ is lower than carrier $C_{l}$ and higher than carrier $C_{2}$, the converter assumes the voltage value $v_{d c \# I} / 2$, the current on the dc side $d c \# 1$ increases, the current $i_{d c \# I P O S}$ increases and the current $i_{d c \# I N E G}$ increases. In this way, the instantaneous power $p_{d c H I P O S}$ increases and the instantaneous power $p_{d c \# I N E G}$ decreases. 
Fig. 4 shows the results obtained during the operation of the BB3L converter in buck-mode, but taking into account that the voltage on the dc side $d c \# 2$ is higher than half the voltage on the dc side $d c \# 1$. In this case, a voltage of $400 \mathrm{~V}$ on the dc side $d c \# 1$ and a voltage of $250 \mathrm{~V}$ on the dc side $d c \# 2$ were considered. The same reasoning used to the detailed description of Fig. 3 can also be used in the analysis of Fig. 4. The current on the dc side $d c \# 2$ $\left(i_{L_{\{}\{1,2\}}\right)$ is properly controlled according to a reference of $10 \mathrm{~A}$ $\left(i^{*}{ }_{\{1,2\}}\right)$. With particular relevance, it can be seen in Fig. $4(\mathrm{e})$ that the voltage assumed by the converter $\left(v_{B B 3 L}\right)$ has the values of $400 \mathrm{~V}$ or $200 \mathrm{~V}$, corresponding to the voltage $v_{d c \# l}$ and half of the voltage $v_{d c \# t}$. The detailed analysis of this figure is very similar to the previous case presented in Fig. 3.

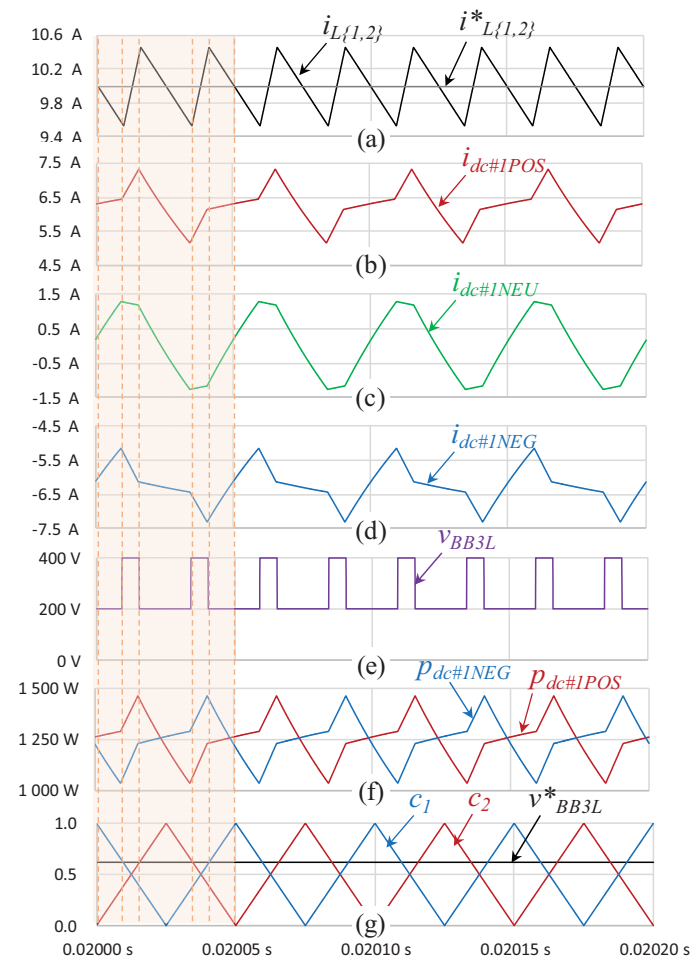

Fig. 4. BB3L dc-dc converter during the operation in buck-mode with the voltage on the dc-side $d c \# 2$ higher than half of the voltage on the dc-side $d c \# 1$ (a) Current on the dc-side $d c \# 2\left(i_{\left.L_{i} 1,2\right\}}\right)$; (b)(c)(d) Currents on the dc-side $d c \# 1$ $\left(i_{d c \# I P O S}, i_{d c \# I N E U}, i_{d c \# I N E G}\right)$; (e) Voltage assumed by the converter $\left(v_{B B 3 L}\right)$; (f) Instantaneous powers on the dc-side $d c \# 1$; (g) PWM carriers $\left(c_{\{1,2\}}\right)$ and reference voltage of the converter $\left(v_{B B 3 L}^{*}\right)$.

\section{B. Operation in Boost-Mode}

Fig. 5 shows the results obtained during the operation of the BB3L dc-dc converter in boost-mode, taking into account that the voltage on the dc side $d c \# 2$ is lower than half the voltage on the dc side $d c \# 1$. In this case, a voltage of $400 \mathrm{~V}$ on the dc side $d c \# 1$ and a voltage of $150 \mathrm{~V}$ on the dc side $d c \# 2$ were considered. Fig. 5(a) shows the current on the dc side $d c \# 2\left(i_{L\{1,2\}}\right)$ properly controlled according to a reference of $10 \mathrm{~A}\left(i^{*}{ }_{L_{\{}\{, 2\}}\right)$. In Fig. 5(b), Fig. 5(c), Fig. 5(d) the currents on the dc-side $d c \# 1$ are shown, respectively, the currents $i_{d c \# I P O S}, i_{d c \# I N E U}$, and $i_{d c \# I N E G \text {. The }}$ voltage $v_{d c \# 2}$ is lower than half of the voltage $v_{d c \# 1}$, therefore the converter assumes the values of $0 \mathrm{~V}$ or $200 \mathrm{~V}$, as shown in Fig. 5(e). Fig. 5(f) shows the instantaneous powers on the dc side $d c \# 1$. Finally, in Fig. $5(\mathrm{~g})$ are shown the carriers and the reference $v_{B B 3 L}^{*}$. The analysis of the five cases is very similar to the presented analysis during the buck-mode.

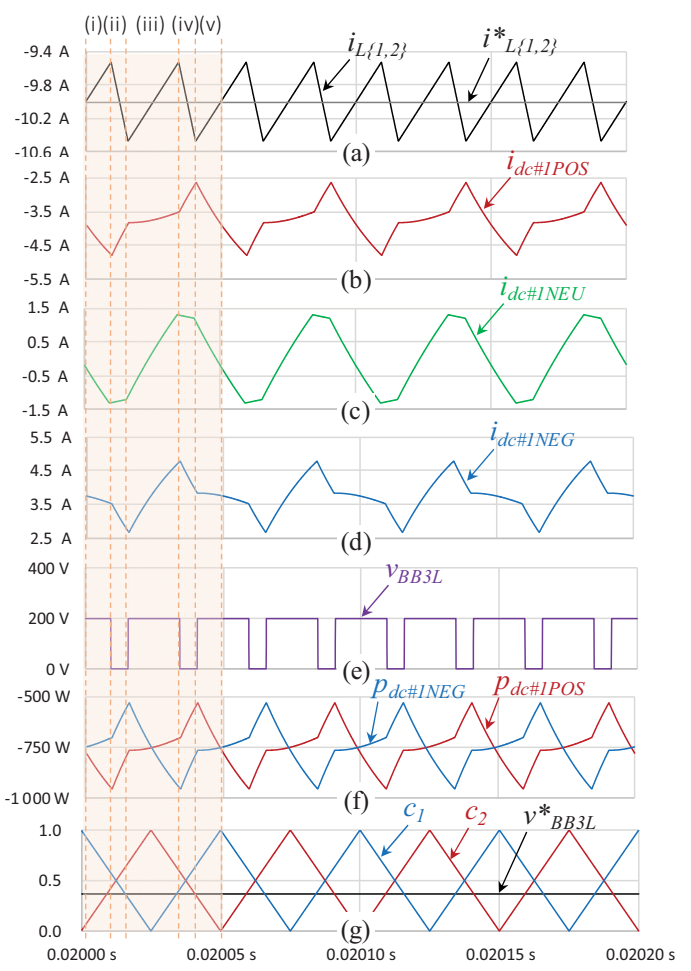

Fig. 5. BB3L dc-dc converter during the operation in boost-mode with the voltage on the dc-side $d c \# 2$ lower than half of the voltage on the dc-side $d c \# 1$ : (a) Current on the dc-side $d c \# 2\left(i_{L\{1,2\}}\right)$; (b)(c)(d) Currents on the dc-side $d c \# 1$ $\left(i_{d c \# I P O S}, i_{d c \# I N E U}, i_{d c \# I N E G}\right)$; (e) Voltage assumed by the converter $\left(v_{B B 3 L}\right)$; (f) Instantaneous powers on the dc-side $d c \# 1$; (g) PWM carriers $\left(c_{\{1,2\}}\right)$ and reference voltage of the converter $\left(v_{B B 3 L}^{*}\right)$.

Fig. 6 shows the results obtained during the operation of the BB3L dc-dc converter in boost-mode, but with a voltage on the dc side $d c \# 2$ higher than half the voltage on the dc side $d c \# 1$. In this case, a voltage of $400 \mathrm{~V}$ on the dc side $d c \# 1$ and a voltage of $250 \mathrm{~V}$ on the dc side $d c \# 2$ were considered. As shown, the current on the dc side $d c \# 2\left(i_{L\{1,2\}}\right)$ is controlled according to the reference $i_{d c \# 2 .}$. In this case, the voltage $v_{B B 3 L}$ assumes the values of $400 \mathrm{~V}$ or $200 \mathrm{~V}$, corresponding to the voltage $v_{d c \# l}$ and half of the voltage $v_{d c \# l}$. The detailed analysis of this figure is very similar to the previous case presented in Fig. 5.

\section{BIPOLAR BIDIRECTIONAL THREE-LEVEL DC-DC CONVERTER: EXPERIMENTAL VALIDATION}

Fig. 7 shows a photography of the BB3L dc-dc converter, which is framed with an ac-dc converter to interface the power grid. The validation was performed with a maximum voltage on the dc side $d c \# 1$ of $400 \mathrm{~V}$ and with a voltage on the dc side $d c \# 2$ of $200 \mathrm{~V}$. The sampling frequency was fixed on $40 \mathrm{kHz}$ and the switching frequency was fixed on half of this value. The digital control was implemented on a TI DSP F28335. The results were registered using a DL716 Yokogawa digital oscilloscope. Fig. 8 shows an experimental result during the buck-mode, where it is possible to verify the current on the dc side $d c \# 1\left(i_{L\{1,2\}}\right)$, and the voltage assumed by the BB3L dc-dc converter $\left(v_{B B 3 L}\right)$, as well as the gate-emitter voltage of the IGBTs $s_{1}$ and $s_{4}\left(v_{g e S}\{1,4\}\right)$. As it is possible to verify, five distinct cases are identified. In case (i), the current $i_{L\{1,2\}}$ is at zero level, meaning that the control is not 
activated. Therefore, the voltage assumed by the converter $\left(v_{B B 3 L}\right)$ is also $0 \mathrm{~V}$. In case (ii), the current $i_{L\{1,2\}}$ increases and, as the voltage $v_{d c \# 2}$ is lower than half of the voltage $v_{d c \# I}$, the voltage $v_{B B 3 L}$ assumes the values of 0 and $v_{d c \# I} / 2$. In case (iii), the current $i_{L_{\{1}\{, 2\}}$ continues to increase and taking into account that the voltage $v_{d c \sharp 2}$ increases until it is higher than half of the voltage $v_{d c \# 1}$, the voltage $v_{B B 3 L}$ assumes the values of $v_{d c \# I} / 2$ and $v_{d c \# 1}$.

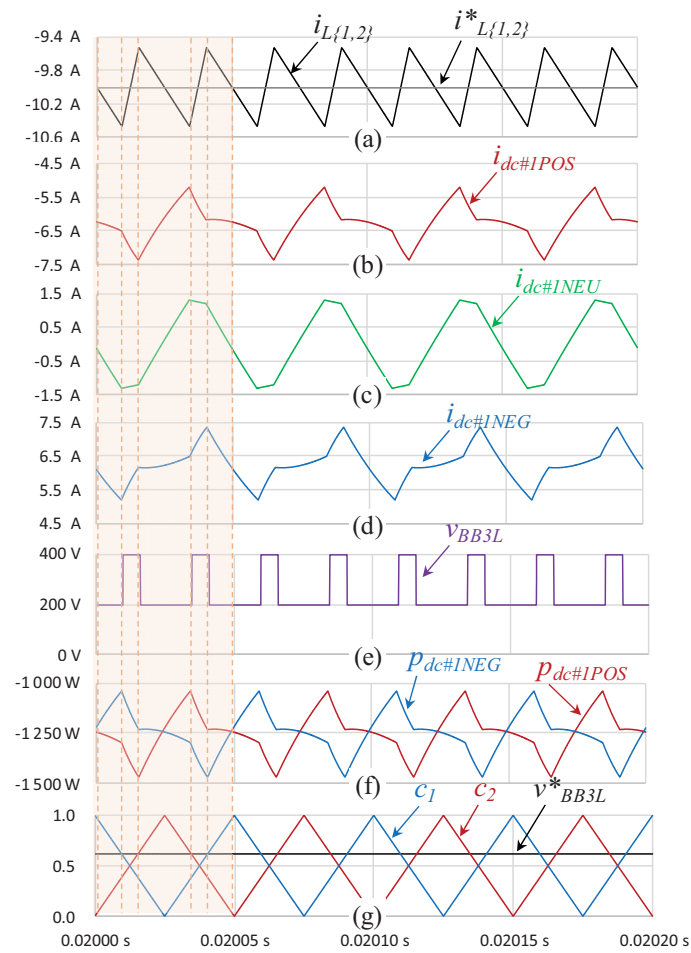

Fig. 6. BB3L dc-dc converter during the operation in boost-mode with the voltage on the dc-side $d c \# 2$ higher than half of the voltage on the dc-side $d c \# 1$ : (a) Current on the dc-side $d c \# 2\left(i_{L \prime 1,2}\right)$; (b)(c)(d) Currents on the dc-side $d c \# I$ $\left(i_{d c \# I P O S}, i_{d c H I N E U}, i_{d c H I N E G}\right)$; (e) Voltage assumed by the converter $\left(v_{B B 3 L}\right)$; (f) Instantaneous powers on the dc-side $d c \# 1$; (g) PWM carriers $\left(c_{\{1,2\}}\right)$ and reference voltage of the converter $\left(v_{B B 3 L}\right)$.

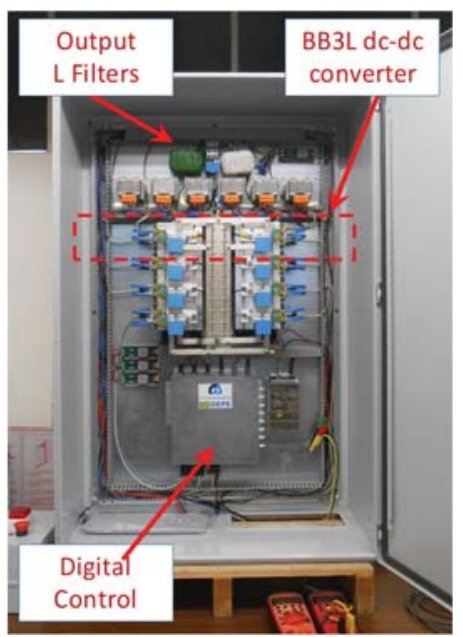

Fig. 7. Photography of the BB3L dc-dc converter framed with an ac-dc converter to interface an ac power grid.

In case (iv) the current decreases and the voltage $v_{d c \# I}$ also decreases, consequently, the $v_{B B 3 L}$ assumes again the values of 0 and $v_{d c \# I} / 2$. In case (v) the current $i_{L\{1,2\}}$ is again at zero level, equal to case (i). Accordingly, it is verified the operation with three voltage levels, only increasing/decreasing the voltage $v_{d c \# 2}$ as a consequence of increasing/decreasing the current $i_{L_{\{1,2\}} \text {. }}$ Fig. 9 shows an experimental result during the boost-mode, where it is possible to verify in detail the current on the de side $d c \# 1\left(i_{L\{1,2\}}\right)$, the voltage assumed by the BB3L dc-dc converter $\left(v_{B B 3 L}\right)$, as well as the gate-emitter voltage of the IGBTs $s_{2}$ and $s_{3}$ ( $v_{\text {ges }\{2,3\}}$, turned on with $15 \mathrm{~V}$ and turned off with $-8 \mathrm{~V}$ ). Analyzing in detail, it is possible to verify that the voltage $v_{B B 3 L}$ assumes the values $v_{d c \# 1}$ and $v_{d c \# I} / 2$, meaning a voltage $v_{d c \# 2}$ higher than half of the voltage $v_{d c \# l}$. More specifically, it is possible to verify that the IGBTs $s_{2}$ and $s_{3}$ are switched with the same switching frequency, but with a phase-shift of 180 degrees. Consequently, the voltage $v_{B B 3 L}$ has a frequency that is the double of the switching frequency.

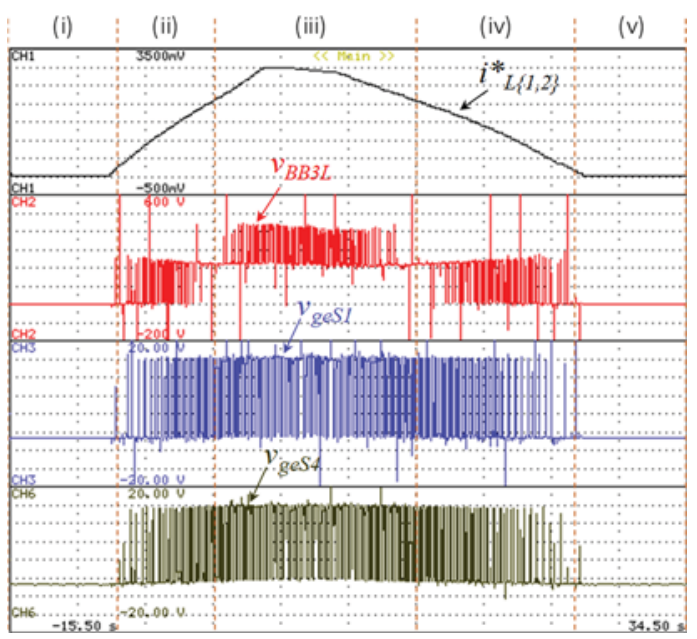

Fig. 8. Experimental results of the BB3L dc-dc converter during the buck-mode: Current on the dc side $d c \# 2 \quad\left(i_{L^{\prime}, 2,2}: 5 \mathrm{~A} / \mathrm{div}\right)$; Three-level voltage $\left(v_{B B 3 L}: 100 \mathrm{~V} / \mathrm{div}\right)$; Gate-emitter voltage of the IGBTs $s_{1}$ and $s_{4}\left(v_{g e s\{1,4\}}: 5 \mathrm{~V} / \mathrm{div}\right)$.

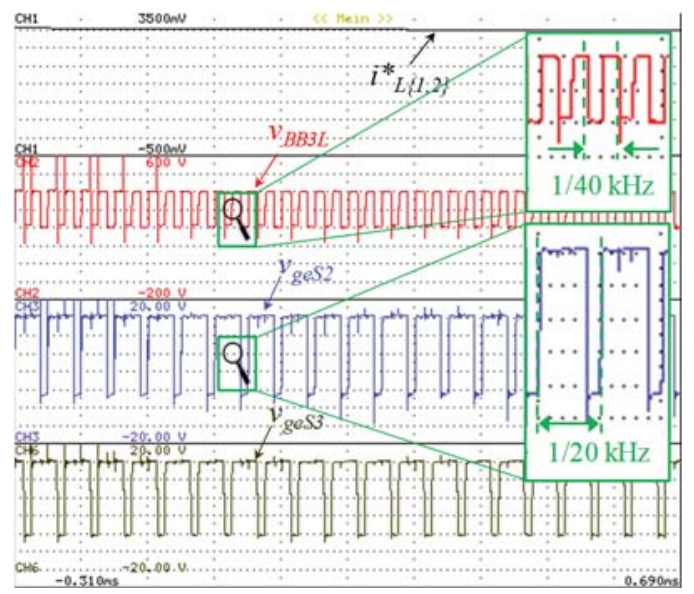

Fig. 9. Experimental results of the BB3L dc-dc converter during the boost-mode: Current on the dc side $d c \# 2\left(i_{L^{\prime}, 2,2}: 5 \mathrm{~A} / \mathrm{div}\right)$; Voltage assumed by the BB3L dc-dc converter $\left(v_{B B 3 L}: 100 \mathrm{~V} / \mathrm{div}\right)$; Gate-emitter voltage of the IGBTs $s_{2}$ and $s_{3}\left(v_{\text {ges }\{2,3\}}\right.$ : $5 \mathrm{~V} / \mathrm{div})$.

\section{CONCLUSIONS}

In this paper, a proposed bidirectional bipolar three-level (BB3L) dc-dc converter is introduced as an important contribution to interface dc technologies into bipolar dc power grids. The description of the topology and the control strategies 
are presented according to the distinct possibilities of operation, highlighting the advantages related with the possibility of operating with three voltage levels, and with the voltage and current variables controlled with the double of the switching frequency. The validation was carried out by means of a laboratory prototype considering operation in buck-mode and boost-mode, as well as the voltage on the dc side $d c \# 2$ higher and lower than half of the voltage on the dc side $d c \# 1$. The obtained results show the advantages of the BB3L dc-dc converter mainly in terms of controlled current, in both buck-mode and boost-mode, for the distinct conditions of voltages on both dc sides, the three voltage levels, and the balanced power in the interface of the bipolar dc power grid (consuming or injecting energy).

\section{ACKNOWLEDGMENT}

This work has been supported by FCT - Fundação para a Ciência e Tecnologia with-in the Project Scope: UID/CEC/00319/2020. This work has been supported by the FCT Project newERA4GRIDs PTDC/EEI-EEE/30283/2017, and by the FCT Project DAIPESEV PTDC/EEI-EEE/30382/2017. Tiago Sousa is supported by the doctoral scholarship SFRH/BD/134353/2017 granted by FCT.

\section{REFERENCES}

[1] A. P. Sakis Meliopoulos, George Cokkinides, Renke Huang, Evangelos Farantatos, Sungyun Choi, Yonghee Lee, Xuebei Yu, "Smart Grid Technologies for Autonomous Operation and Control," IEEE Trans. Smart Grid, vol.2, no.1, pp.1-10, Mar. 2011.

[2] Vehbi C. Gungor, Dilan Sahin, Taskin Kocak, Salih Ergut, Concettina Buccella, Carlo Cecati, Gerhard P. Hancke, "Smart Grid and Smart Homes - Key Players and Pilot Projects," IEEE Ind. Electron. Mag., vol.6, pp.18-34, Dec. 2012.

[3] Xinghuo Yu, Carlo Cecati, Tharam Dillon, M. Gody Simoes, "The New Frontier of Smart Grids: An Industrial Electronics Perspective," IEEE Ind. Electron. Mag. vol.5, no.3, pp.49-63, Sept. 2011.

[4] Vitor Monteiro, Andres A. Nogueiras Melendez, Joao C. Ferreira, Carlos Couto, Joao L. Afonso, "Experimental Validation of a Proposed SinglePhase Five-Level Active Rectifier Operating with Model Predictive Current Control," IEEE IECON Industrial Electronics Conference, pp.3939-3944, Nov. 2015.

[5] Vitor Monteiro, Joao C. Ferreira, Andres A. Nogueiras Melendez, Joao L. Afonso, "Model Predictive Control Applied to an Improved Five-Level Bidirectional Converter," IEEE Trans. Ind. Electron., vol.63, no.9, pp.5879-5890, Sept. 2016.

[6] Vitor Monteiro, Joao C. Ferreira, Andres A. Nogueiras Melendez, Carlos Couto, Joao L. Afonso, "Experimental Validation of a Novel Architecture Based on a Dual-Stage Converter for Off-Board Fast Battery Chargers of Electric Vehicles," IEEE Trans. Veh. Tech., vol.67, no.2, pp.1000-1011, Feb. 2018.

[7] Hossein Lotfi, Amin Khodaei, "AC Versus DC Microgrid Planning," IEEE Trans. Smart Grid, vol.8, no.1, pp.296-304, Jan. 2017.

[8] P. Fairley, "DC versus AC: the second war of currents has already begun [In My View]," IEEE Power Energy Mag., vol.10, no.6, pp.104-103, Nov. 2012.

[9] Tomislav Dragicevic, Xiaonan Lu, Juan C. Vasquez, Josep M. Guerrero, "DC Microgrids-Part I: A Review of Control Strategies and Stabilization Techniques," IEEE Trans. Power Electron., vol.31, no.7, pp.4876-4891, July 2016.

[10] Tomislav Dragicevic, Xiaonan Lu, Juan C. Vasquez, Josep M. Guerrero, "DC Microgrids-Part II: A Review of Power Architectures, Applications, and Standardization Issues," IEEE Power Electron., vol.31, no.5, pp.3528-3549, May 2016.

[11] Enrique Rodriguez-Diaz, Fang Chen, Juan C. Vasquez, Josep M. Guerrero, Rolando Burgos, Dushan Boroyevich, "Voltage-Level Selection of Future Two-Level LVdc Distribution Grids: A Compromise Between Grid Compatibiliy, Safety, and Efficiency," IEEE Electrification Magazine, vol.4, no.2, pp.20-28, June 2016.

[12] Daniel Salomonsson, Ambra Sannino, "Low-Voltage DC Distribution
System for Commercial Power Systems With Sensitive Electronic Loads," IEEE Trans. Power Del., vol.22, no.3, pp.1620-1627, July 2007.

[13] Xialin Li, Li Guo, Chao Hong, Ye Zhang, Yun Wei Li, Chengshan Wang, "Hierarchical Control of Multiterminal DC Grids for Large-Scale Renewable Energy Integration,” IEEE Trans. Sustain. Energy, vol.9, no.3, pp.1448-1457, July 2018.

[14] Kaiqi Sun, Ke-Jun Li, Zhuo-di Wang, Huadong Sun, Mingqiang Wang, Zhijie Liu, Meiyan Wang, "Operation Modes and Combination Control for Urban Multivoltage-Level DC Grid,” IEEE Trans. Power Del., vol.33, no.1, pp.360-370.

[15] Kumars Rouzbehi, Jose Ignacio Candela, Alvaro Luna, Gevork B. Gharehpetian, Pedro Rodriguez, "Flexible Control of Power Flow in Multiterminal DC Grids Using DC-DC Converter," IEEE J. Emerg. Sel. Topics Power Electron., vol.4, no.3, pp.1135-1144, Sept. 2016.

[16] Jianjun Ma, Miao Zhu, Xu Cai, Yun Wei Li, "DC Substation for DC Grid-Part I: Comparative Evaluation of DC Substation Configuration," IEEE Trans. Power Electron., vol.34, no.10, pp.9719-9731, Oct. 2019.

[17] Jianjun Ma, Miao Zhu, Xu Cai, Yun Wei Li, "DC Substation for DC Grid-Part II: Hierarchical Control Strategy and Verification," IEEE Trans. Power Electron., vol.34, no.9, pp.8682-8696, Sept. 2019.

[18] Tomislav Dragicevic, Juan C. Vasquez, Josep M. Guerrero, Davor Skrlec, "Advanced LVDC Electrical Power Architectures and Microgrids: A step toward a new generation of power distribution networks," IEEE Electrification Magazine, vol.2, no.1, pp.54-65, Mar. 2014.

[19] Umamaheswararao Vuyyuru, Suman Maiti, Chandan Chakraborty, "Active Power Flow Control Between DC Microgrids," IEEE Trans. on Smart Grid, vol.10, no.5, pp.5712-5723, Sept. 2019.

[20] Dushan Boroyevich, Igor Cvetkovic, Rolando Burgos, Dong Dong, "Intergrid: A Future Electronic Energy Network?," IEEE J. Emerg. Sel. Topics Power Electron., vol.1, no.3, pp.127-138, Sept. 2013.

[21] Juan David Paez, David Frey, Jose Maneiro, Seddik Bacha, Piotr Dworakowski, "Overview of DC-DC Converters Dedicated to HVdc Grids,” IEEE Trans. Power Del., vol.34, no.1, pp.119-128, Feb. 2019.

[22] Zmarrak Wali Khan, Han Minxiao, Che Kai, Liu Yang, Atiq ur Rehman, "State of the Art DC-DC Converter Topologies for the Multi-Terminal DC Grid Applications: A Review," IEEE PESGRE International Conference on Power Electronics, Smart Grid and Renewable Energy, pp.1-7, Jan. 2020

[23] Jafar Mohammadi, Firouz Badrkhani Ajaei, Gary Stevens, "Grounding the DC Microgrid,” IEEE Trans. Ind. Appl., vol.55, no.5, pp.4490-4499, Sept. 2019.

[24] European Parliament, "Directive 2014/35/EU of the European Parliament and of the Council," Official Journal of the European Union, vol.L96, pp. 357-374, Mar. 2014.

[25] Yunjie Gu, Wuhua Li, Xiangning He, "Analysis and Control of Bipolar LVDC Grid With DC Symmetrical Component Method,” IEEE Trans. Power Syst., vol.31, no.1, pp.685-694, Jan. 2016.

[26] Hiroaki Kakigano, Yushi Miura, Toshifumi Ise, "Low-Voltage BipolarType DC Microgrid for Super High Quality Distribution," IEEE Trans. vol.25, no.12, pp.3066-3075, Dec. 2010.

[27] Sebastian Rivera, Ricardo Lizana, Samir Kouro, Tomislav Dragicevic, Bin Wu, "Bipolar DC Power Conversion: State-of-the-Art and Emerging Technologies," IEEE Journal of Emerging and Selected Topics in Power Electronics, 2020.

[28] Jackson Lago, Marcelo Lobo Heldwein, “Operation and Control-Oriented Modeling of a Power Converter for Current Balancing and Stability Improvement of DC Active Distribution Networks," IEEE Trans., vol.26, no.3, pp.877-885, Mar. 2011.

[29] Sebastian Rivera, Bin Wu, "Electric Vehicle Charging Station With an Energy Storage Stage for Split-DC Bus Voltage Balancing," IEEE Trans., Power Electron., vol.32, no.3, pp.2376-2386, Mar. 2017.

[30] K. T. Tan, B. Sivaneasan, X. Y. Peng, P. L. So, "Control and Operation of a DC Grid-Based Wind Power Generation System in a Microgrid," IEEE Trans. Energy Convers., vol.31, no.2, pp.496-505, June 2016.

[31] Bo Yang, Bingyu Sang, Zhihan Yang, Menbo Li, Wang Xiang, Xiaojun Lu, Liangzhong Yao, Yibin Tao, "Coordinated Control Strategy of a DC Grid with Energy Storage System," International Conference on Renewable Power Generation, Beijing, pp.1-6, 2015.

[32] B. T. Patterson, "DC, Come Home: DC Microgrids and the Birth of the 'Enernet',' IEEE Power and Energy Magazine, vol.10, no.6, pp.60-69, Nov.-Dec. 2012. 